
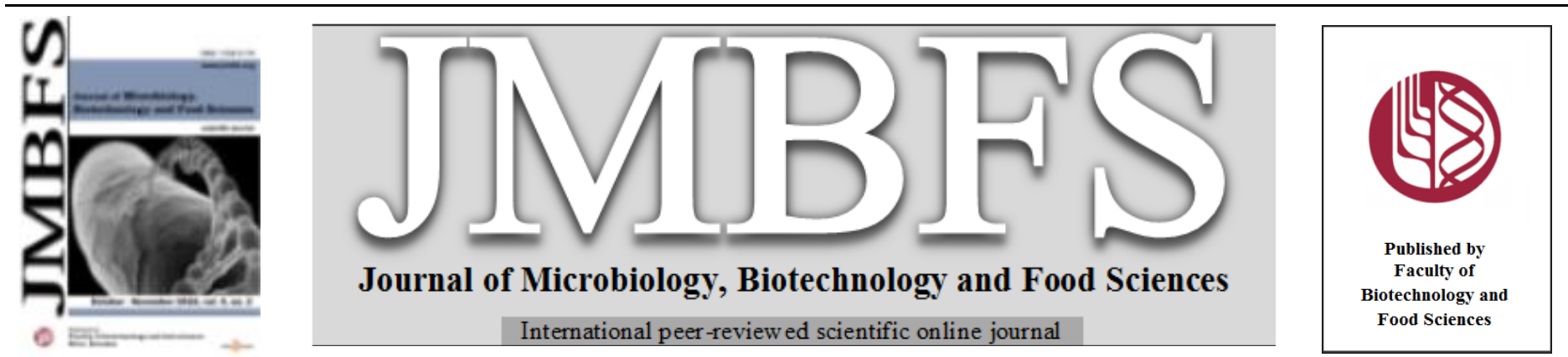

\title{
PCR-DGGE ANALYSIS OF THE YEAST POPULATION ASSOCIATED WITH NATURAL FERMENTATION OF TABERNA
}

\author{
Jorge A. Santiago-Urbina ${ }^{1,3}$, Carolina Peña-Montes ${ }^{1}$, Hipócrates Nolasco-Cancino ${ }^{1,2,3}$, Francisco Ruiz-Terán $^{l} *$
}

\author{
Address(es): Dr. Francisco Ruiz-Terán, \\ ${ }^{1}$ Universidad Nacional Autónoma de México, Facultad de Química, Departamento de Alimentos y Biotecnología, Avenida Universidad 3000,04510 Ciudad de \\ México, México, Tel.: +52 5556225311 . \\ ${ }^{2}$ Universidad Autónoma Benito Juárez de Oaxaca, Facultad de Ciencias Químicas, Avenida Universidad S/N, 68120 Oaxaca de Juárez, México. \\ ${ }^{3}$ Consultoria e Investigación en Ciencias Químicas Nisa Nabani SC, Avenida Fuerza Aérea Mexicana 607, 68050 Oaxaca de Juárez, México.
}

*Corresponding author: panchote@unam.mx

doi: 10.15414/jmbfs.2016.6.2.758-763

\section{ARTICLE INFO}

Received 4. 12. 2015

Revised 5. 3. 2016

Accepted 27. 4. 2016

Published 3. 10. 2016

Regular article

OPEN OACCESS

\begin{abstract}
In this study, yeast community associated with the natural fermentation of Taberna, an alcoholic beverage made from palm sap, was determined using PCR-denaturing gradient gel electrophoresis (PCR-DGGE) of the D1 region of the 26S rRNA gene. This technique was complemented by cloning and sequencing of DGGE bands. The experiments were performed in triplicate. Each palm tree (palm tree I, II and III) represented an experimental unit. Fourteen batches from each palm tree were analyzed. These molecular methods allowed a rapid monitoring of yeast population associated with Taberna fermentation. Most frequent yeast species were Hanseniaspora guilliermondii, Saccharomyces cerevisiae and Pichia kudriavzevii (Issatchenkia orientalis), followed by Candida tropicalis and Kazachstania exigua. In addition, Meyerozyma guilliermondii, Candida akabanensis, Candida blattae, Candida intermedia, Pichia kluyveri and Trichosporon moniliiforme were also detected. In the first batches, only 5 yeast species were identified, from the second batch the number of species increased, in some batches ten yeast species were identified. The implementation of PCR-DGGE to describe yeast population in fermentation of Taberna revealed new members (C. akabanensis, C. blattae and T. moniliiforme) related with this palm wine. Results showed that PCR-DGGE is a good technique for characterizing yeast population structure. Findings allowed us gain important information about yeast community structure of Taberna fermentation.
\end{abstract}

Keywords: Palm wine, Acrocomia aculeata, Yeast, DGGE, Taberna

\section{INTRODUCTION}

Taberna is a traditional palm wine produced by the natural fermentation of the sap obtained from a palm tree named Acrocomia aculeata ("coyol" palm tree). This beverage is consumed as a refreshing and alcoholic drink in small villages in southeast of Mexico and Central America (Balick, 1990; Alcántara-Hernández et al., 2010). The production process of Taberna has been previously reported by Santiago-Urbina et al. (2013, 2015). Palm sap is obtained from the stem of felled palm trees through a series of steps which involve the perforation in the apical part of the stem. The receptacle is known as canoe (place where the sap is accumulated and naturally fermented), which is scraped every day. The main sugar of the coyol palm sap is sucrose, about $11 \%$ (Santiago-Urbina et al., 2013). Two batches of Taberna are harvested daily. Each one has a different chemical composition: ethanol content ( 0.21 to $4.78 \%$ ), sugar content (1 to 8\%), lactic acid (0.05 to $0.5 \% \mathrm{w} / \mathrm{v})$, acetic acid $(0.01-0.24 \% \mathrm{w} / \mathrm{v})$ and $\mathrm{pH}(6$ to 4$)$ (Santiago-Urbina et al., 2013). The fermentation of Taberna is a natural and non-controlled process that involves lactic acid bacteria, acetic acid bacteria and yeast (Alcántara-Hernández et al., 2010; Santiago-Urbina et al., 2015). Yeasts have been reported to be important in the fermentation process of different types of palm wine such as those produced in Ghana, Cameroon and Burkina Faso (Amoa-Awua et al., 2007; Stringini et al., 2009; Ouoba et al., 2012). There is a limited knowledge about the yeasts population on Taberna fermentation. Based on isolation and PCR-RFLP analysis followed by sequencing of the domain D1/D2 of the 26S rDNA Santiago-Urbina et al. (2015) have identified Kazachstania unispora, $K$. exigua, $C$. tropicalis, $C$. intermedia, $M$ guilliermondii, $P$. kudriavzevii (I. orientalis), H. guilliermondii and P. kluyveri as yeast species involved in this fermentation. Although, culture-dependent techniques provide significant insight, it may not reflect the complete yeast population. Ampe et al. (1999) have reported that at least $25-50 \%$ of the active microbial community of fermented foods cannot be cultivated in the laboratories conditions. To complete and overcome this challenge, a culture-independent molecular approach using Polymerase Chain Reaction-Denaturing Gradient Gel
Electrophoresis (PCR-DGGE) has been employed, and it is a well documented method for analysis of microbial communities in fermented foods (Stringini $\boldsymbol{e} t$ al., 2009; Osimani et al., 2015; Puerari et al., 2015; Valera et al., 2015). PCRDGGE is a molecular tool used and recommended for microbial community structure analysis (Neilson et al., 2013). The objective of this study was to identify the yeast population associated with Taberna fermentations using PCR DGGE as a culture-independent technique. The information obtained in this investigation will help to improve the knowledge about the microbiology of this palm wine.

\section{MATERIAL AND METHODS}

\section{Taberna samples}

Taberna production is similar to fed-batch fermentation, because the sap flow is constant and accumulated in the canoe until it is full. Fermented sap (Taberna) is harvested in the morning and in the afternoon. In the morning when the receptacle is empty, the producer scrapes the walls of the canoe in order to amplify the size of it. In this work each sample collected corresponds to the final product (Taberna) of a batch, i.e. when the canoe is full ( $12 \mathrm{~h}$ approximately). Experiments were conducted in triplicate. Each palm tree (I, II and III) corresponded to an experimental unit. Samples of Taberna were collected from 14 batches from each palm tree. In addition, one sample of fresh sap (unfermented sap taken immediately after the producer opened the canoe) was evaluated with the aim of determining the initial yeast population. Samples were harvested in March 2012 in Benito Juárez, Chiapas, Mexico as described in Santiago-Urbina et al. (2013, 2015). From each batch, approximately $50 \mathrm{~mL}$ of palm sap was taken directly from the canoe. The samples were collected into presterilized 50-mL Falcon tubes in the morning $(6: 00 \mathrm{am})$, before the canoe scraping was performed. 


\section{Extraction of total microbial DNA}

The Taberna samples were processed as follows: in order to remove the residue of palm tree bark in the palm wine, $50-\mathrm{mL}$ of sample was filtered through sterile gauze. Then, $10-\mathrm{mL}$ of each filtered sample was centrifuged at $11600 \mathrm{x} \mathrm{g}$ at $4{ }^{\circ} \mathrm{C}$ for $10 \mathrm{~min}$. After that, the pellets were washed using wash solution $1(50 \mathrm{mM}$ Tris- $\mathrm{HCl} \mathrm{pH} 8.3,200 \mathrm{mM} \mathrm{NaCl}, 5 \mathrm{mM} \mathrm{Na} 2$ EDTA, $0.05 \%$ Triton X-100), wash solution 2 (50 mM Tris- $\mathrm{HCl} \mathrm{pH} 8.3,200 \mathrm{mM} \mathrm{NaCl}, 5 \mathrm{mM} \mathrm{Na} 2$ EDTA) and wash solution 3 (10 mM Tris-HCl pH 8.3, $0.1 \mathrm{mM} \mathrm{Na} 2$ EDTA) following the wash protocol described in Fortin et al. (2004). Finally, the total DNA of the pellets was extracted using a MasterPure ${ }^{\mathrm{tm}}$ Yeast DNA Purification kit (Epicentre ${ }^{\circledR}$ an Illumina company, USA, Madison) according to the manufacturer's instructions.

\section{PCR-DGGE protocol}

Thirty nanograms of Total DNA were used as template in PCR amplification of the D1 region of the 26S rRNA gene using the primers NL1GC and LS2 (Cocolin et al., 2000). PCR was performed in total volume of $50 \mu \mathrm{L}$ containing 1x PCR Buffer, $2.5 \mathrm{mM} \mathrm{MgCl}_{2}, 0.2 \mathrm{mM}$ of each deoxynucleoside triphosphates (dNTPs), $0.2 \mu \mathrm{M}$ of each primer and $2.5 \mathrm{U}$ of Taq polymerase. The amplification reactions were performed in a thermal cycler (PIKO 24 thermal cycler, Thermo Scientific, Finland , Vantaa) as follows: $5 \mathrm{~min}$ at $95^{\circ} \mathrm{C}, 35$ cycles of $1 \mathrm{~min}$ at 95 ${ }^{\circ} \mathrm{C}, 45 \mathrm{~s}$ at $55^{\circ} \mathrm{C}, 1 \mathrm{~min}$ at $72{ }^{\circ} \mathrm{C}$, and then a final step at $72{ }^{\circ} \mathrm{C}$ for $7 \mathrm{~min}$. Five microliters of each PCR product was analyzed by electrophoresis in $1 \%(\mathrm{w} / \mathrm{v})$ agarose gel in 0.5x TBE (44.5 mM Tris (Sigma-Aldrich, USA, Missouri), 44.5 $\mathrm{mM}$ boric acid (Sigma-Aldrich), $1 \mathrm{mM} \mathrm{Na}$-EDTA (Sigma-Aldrich)) containing $0.7 \mu \mathrm{g} / \mathrm{mL}$ of ethidium bromide (Bio-Rad, USA, California) at $100 \mathrm{~V}$ during 50 min, using a standard molecular weight marker (1 kb plus DNA ladder; Invitrogen, USA, California). Gels were photographed under transilluminated ultraviolet (UV) light with Kodak Molecular Imaging Software version 5.0 (Carestream Health, Inc, USA, New York). The PCR products were analyzed by DGGE using a Bio-Rad Dcode ${ }^{\mathrm{tm}}$ universal mutation detection system (Bio-Rad). PCR samples were directly applied onto $8 \%(\mathrm{w} / \mathrm{v})$ polyacrylamide gels $(0.8 \mathrm{~mm})$ in a running buffer ( $1 \mathrm{x}$ TAE) containing $0.04 \mathrm{mM}$ Tris base; $0.02 \mathrm{M}$ acetic acid, glacial; $1 \mathrm{mM}$ EDTA, $\mathrm{pH}$ 8. Denaturing conditions were first determined using a perpendicular gradient gel and DNA of the yeast species previously isolated and identified. The gels were prepared with a denaturing gradient from 25 to $60 \%$ of urea and formamide (100\% corresponds to $7 \mathrm{M}$ urea and $40 \%$ (w/v) formamide) and an acrylamide and bis-acrylamide ratio of 19:1 (poliacrylamyde mixing powder, Sigma-Aldrich). Electrophoresis was performed at a constant voltage and temperature of $70 \mathrm{~V}$ and $60{ }^{\circ} \mathrm{C}$ for $17 \mathrm{~h}$. After electrophoresis the gels were stained using a silver-staining method described by Byun et al. (2009), photographed and analyzed with Kodak Molecular Imaging Software version 5.0 (Carestream Health, Inc.). Batches were grouped based on the DGGE profiles using unweighted pair group average (UPGMA) cluster analysis based on the Dice similarity coefficient using the PAST software, version $2.17 \mathrm{c}$.

\section{DGGE band sequencing}

DGGE bands of interest were excised from the gels with a sterile scalpel and placed into sterile Eppendorf tubes containing $50 \mu \mathrm{L}$ of sterile deionized water. Tubes were incubated overnight at $4{ }^{\circ} \mathrm{C}$ to allow diffusion of DNA. Ten nanograms of each eluate were then used as a DNA template for a PCR using the primers NL1 and LS2 and the conditions described above. The PCR products were purified using a DNA Clean and Concentrator ${ }^{\mathrm{tm}}-5$ (Zymoresearch, USA, California), and sent for sequencing to Laragen Company (USA, California). Sequences were aligned in GenBank using the Blast program (Altschul $\boldsymbol{e t}$ al., 1997) for identification.

\section{Cloning of the PCR products of DGGE bands}

When many ambiguous peaks in the sequences were obtained, the bands were then cloned by using CloneJet PCR cloning Kit (Thermo scientific, Lithuania).
Purified PCR products amplified from eluted DGGE bands were ligated into pJET1.2/blunt Cloning Vector according to the manufacturer's instructions (CloneJet PCR Cloning kit, thermo scientific, Lithuania), and transformed into Escherichia coli DH5 $\alpha$ cells by chemotransformation. To confirm the presence of insert, five representative colonies were randomly selected and picked. The picked colonies were resuspended in $20 \mu \mathrm{L}$ of mix PCR containing 1x PCR Buffer, $1.5 \mathrm{mM} \mathrm{MgCl}_{2}, 0.2 \mathrm{mM}$ of each deoxynucleoside triphosphates (dNTPs), $0.2 \mu \mathrm{M}$ of each primer and $0.5 \mathrm{U}$ of Taq polymerase. The amplification reactions were performed in a thermal cycler (PIKO 24 thermal cycler, Thermo Scientific) as follows: $5 \mathrm{~min}$ at $95^{\circ} \mathrm{C}, 35$ cycles of $1 \mathrm{~min}$ at $95^{\circ} \mathrm{C}, 45 \mathrm{~s}$ at $55^{\circ} \mathrm{C}, 1 \mathrm{~min}$ at 72 ${ }^{\circ} \mathrm{C}$, and then a final step at $72{ }^{\circ} \mathrm{C}$ for $7 \mathrm{~min}$. Five microliters of each PCR product were analyzed by electrophoresis in agarose gel $(1 \%(\mathrm{w} / \mathrm{v}))$ as described above. Positive clones were confirmed by the amplification of a PCR product of approximately $340 \mathrm{bp}$ length containing the $250 \mathrm{bp}$ D1 region of the $26 \mathrm{~S}$ rRNA gene. Reamplification, sequencing, alignment and identification of cloned PCR products were performed as described previously in DGGE band sequencing section.

\section{Principal component analysis (PCA) and frequency percentage}

Data of the yeast species identified in each batch was converted to a presence (1) absence (0) matrix, and subjected to principal component analysis to investigate the relationships between yeast species and batches from each palm tree Analysis was performed using the free software package PAST (Paleontology statistics, http://folk.uio.no/ohammer/past/).

To study the species distribution in our samples, the method proposed by Solieri et al. (2006) was used. The frequency was estimated as the number of positive samples for a species divided by the total number of samples expressed as a percentage.

\section{RESULTS}

\section{Yeast community fingerprinting patterns}

Fourteen batches of Taberna from each palm tree (palm tree I, palm tree II and palm tree III) and one sample of fresh sap were analyzed through PCR-DGGE. DGGE fingerprints obtained from the total DNA extracted from each sample are shown in Fig. 1. Each vertical lane represents a Taberna sample corresponding to one batch, and each band or spot represents yeast species. A total of 29 bands with different position in the DGGE were obtained. The DGGE fingerprints of batches from palm tree I consisted of 21 bands, resembling to those of palm tree III. Whereas, the profile of the batches in palm tree II involved 19 bands Fourteen bands (a, b, d, e, f, g, h, k, l, q, t, u, x and $\mathrm{z}$ ) were common in the batches of the three palm trees, and fifteen bands were distributed among them (bands c, i, j, o, r were present only in palm tree I; bands oo and nn were present in palm tree II; bands $\mathrm{v}, \mathrm{w}, \mathrm{bb}$, cc were present in palm tree III; band $\mathrm{n}$ was present in palm trees I and III; band p was present in palm trees I and II; bands aa and dd were present in palms II and III). Cluster analysis was carried out using DGGE data to estimate the order of relatedness among the different batches (Fig. 2). DGGE profiles from each batch were mainly clustered in the groups A, B, E, $\mathrm{F}$ and $\mathrm{H}$, which had equal or greater similarity than $65 \%$ (Fig. 2). First batches from each palm tree were grouped in A (batches 2-8), B (batches 2-6) and $\mathrm{H}$ (batches 4-10) clusters. Batches (10-14) from the palm tree I were grouped in cluster E, and batches (9-13) from the palm tree II were grouped in cluster F. A low similarity $(35 \%)$ was obtained between cluster $\mathrm{K}$ (including the first batch of each palm tree) and the cluster L (including most the final batches) (Fig. 2). The cluster analysis showed that the similarities between batches from the same palm tree $(55-100 \%)$ are most closed than the similarities among batches from different palm trees (33-60\%). To determine the identity of each band in the DGGE profile of the samples, the DNA in the band was eluted, reamplified and sequenced. 


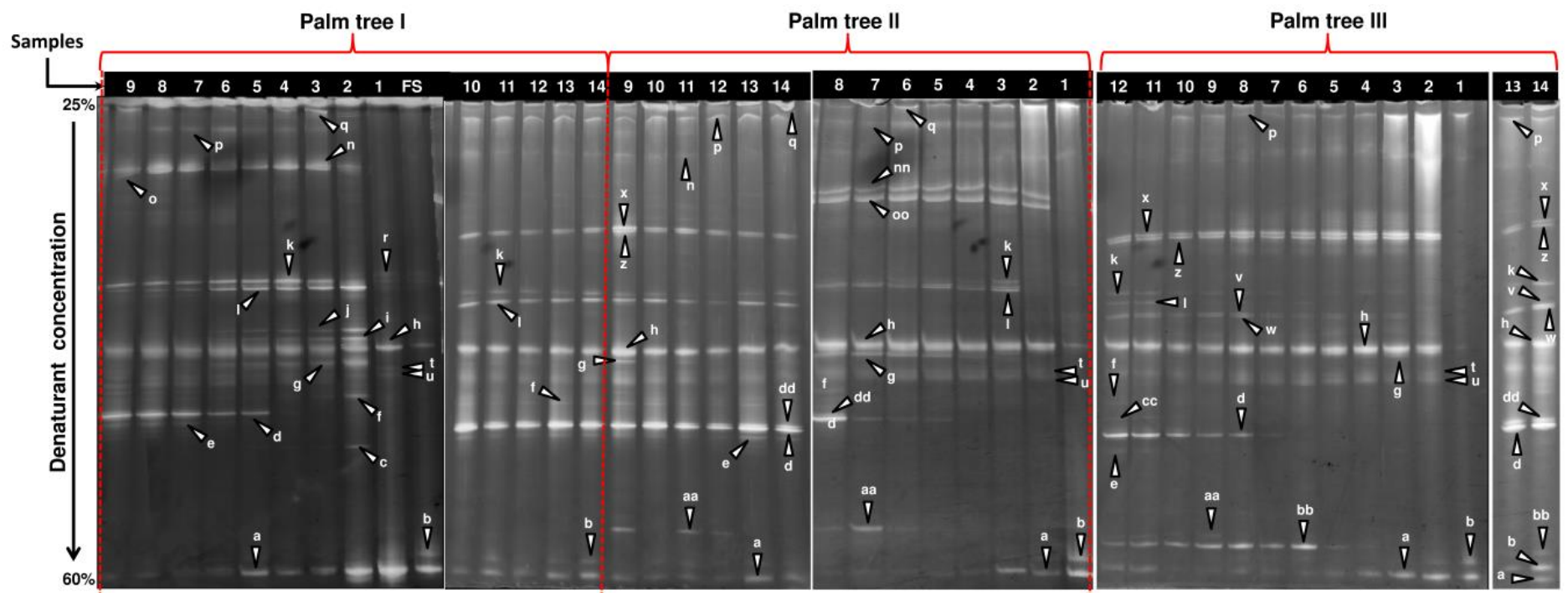

Figure 1 DGGE profiles of the yeasts present in different batches of Taberna from three coyol palm tree. Line FS represents to fresh sap (FS) for all three palm trees, because the sap from each palm tree was mixed (for more volume) and only the one mixed sample was analyzed. Lanes 1 to 14 indicate the number of batch. Band a-P. kudriavzevii, band b-C. akabanensis, $M$. guilliermondii and $S$. cerevisiae, band $\mathrm{c}-K$. exigua, band $\mathrm{d}-S$. cerevisiae, band $\mathrm{e}-S$. cerevisiae, band $\mathrm{f}-K$. exigua and $P$. kluyveri, band $\mathrm{g}-C$. tropicalis, band $\mathrm{h}-H$. guilliermondii, band $\mathrm{i}-M$. guilliermondii, band $\mathrm{j}-C$. akabanensis, band $\mathrm{k}-S$. cerevisiae, band $\mathrm{l}-\mathrm{S}$. cerevisiae, band $\mathrm{n}-\mathrm{S}$. cerevisiae, band $\mathrm{o}-H$. guilliermondii, band $\mathrm{p}-H$. guilliermondii, band $\mathrm{q}-\mathrm{S}$. cerevisiae, band $\mathrm{r}-M$. guilliermondii, band $\mathrm{t}-K$. exigua and $C$. tropicalis, band $\mathrm{u}-H$. guilliermondii, band $\mathrm{v}-H$. guilliermondii, band $\mathrm{w}-H$. guilliermondii, band $\mathrm{x}-C$. akabanensis, $H$. guilliermondii and $C$. blattae, band $\mathrm{z}-H$. guilliermondii, band aa-T. moniliiforme, M. guilliermondii and H. guilliermondii, band bb-K.exigua, band cc-H. guilliermondii and $S$. cerevisiae, band dd-S. cerevisiae, band nn-H. guilliermondii, band oo- $H$. guilliermondii, C. blattae and $C$. intermedia

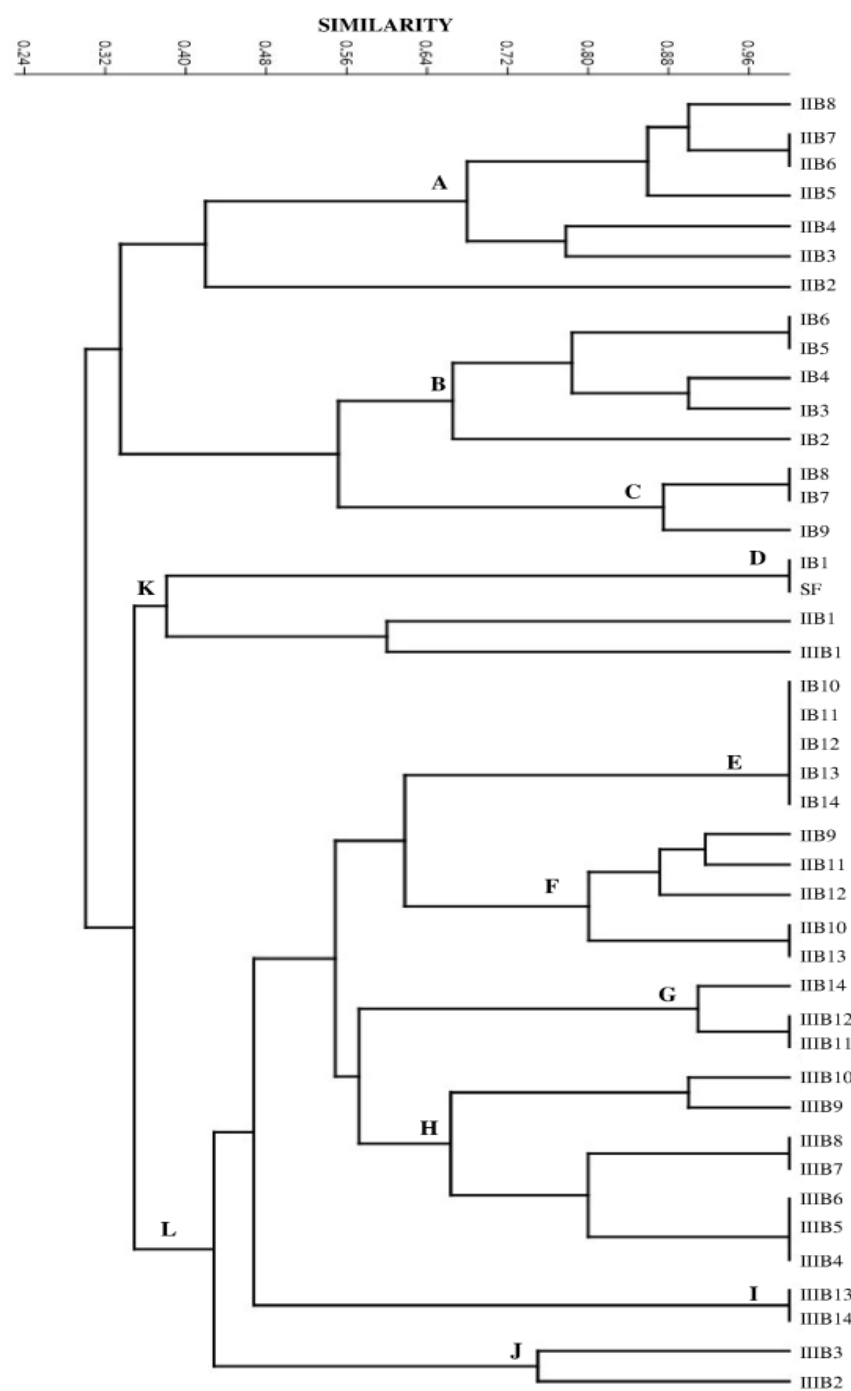

Figure 2 Dendogram based on UPGMA clustering of Dice similarity coefficients of yeasts community PCR-DGGE fingerprintings of different batches of Taberna. I-palm tree I, II-palm tree II, III-palm tree III, B-Batch, 1 to 14-number of batch. A, B, C, D, E, F, G, H, I, J-groups $\geq 65 \%$ of similarity.

\section{Yeast identification by sequencing bands}

From excised bands across all samples and gels, it was possible to assign an identity to 19 of 29 total sequences. The closest relative of the sequences obtained are shown in Table 1 . Bands d, e, k, $1, \mathrm{n}, \mathrm{q}$ and dd were related with $S$ cerevisiae. While, bands $\mathrm{h}, \mathrm{o}, \mathrm{p}, \mathrm{u}, \mathrm{w}, \mathrm{z}$ and $\mathrm{nn}$ were identified as $H$. guilliermondii, the bands $\mathrm{i}$ and $\mathrm{r}$ belonging to the species $M$. guilliermondii and the band bb corresponds to $K$. exigua. The results showed multiband profiles associated with single species; DNA sequences had the same phylogenetic assignment, although their migration profile on the DGGE was different. On the other hand, the resulting sequences of the bands $a, b, f, g, t, v, x, a a, c c$ and oo failed due to the presence of many ambiguous peaks. To determine the identity of these bands in the DGGE profile of the samples, the DNA in the bands were cloned, and five clones for each band were selected in order to identify clones with the insert of interest. In this step, bands a, b, f, g, t, v, aa and cc presented clones with insert of $350 \mathrm{bp}$ and insert with $200 \mathrm{bp}$. The latter is an undesirable fragment, which can be an artefact of PCR and their presence may be associated with the multiple sequences for a single band. In addition, the results showed that a single band may consist of two or three yeast species as indicated in the Table 2. With the cloning of DGGE band, it was possible to identify $P$. kudriavzevii, $P$. kluyveri, C. tropicalis, C. blattae and T. moniliiforme.

In the fresh sap of the coyol palm, the bands a, b, h, k and $\mathrm{r}$ were detected (Fig. 1, lane 1). Band "a" corresponds to P. kudriavzevii, while band "b" represented three yeast species: $M$. guilliermondii, C. akabanensis and S. cerevisiae. These results indicate the co-migration of different DNA fragments in the same position. Band " $h$ " was identified as $H$. guilliermondii, band " $\mathrm{k}$ " was related with $S$. cerevisiae and band " $r$ " was associated with $M$. guilliermondii. From batch 3 , an increase in the number of bands was observed (Fig. 1, lane 3). Thus, bands $f$, $\mathrm{g}, \mathrm{l}, \mathrm{n}, \mathrm{q}, \mathrm{t}$ and $\mathrm{u}$ were detected in the batches of the three palm trees. Additionally, bands c, i and $\mathrm{j}$ were observed in the batch of palm tree $\mathrm{I}$, as well as bands nn and oo in palm tree II. Band "f" contained two species, $K$. exigua and $P$. kluyveri, while band "g" was assigned to C. tropicalis, which predominated in the batches of palm tree I and II. Bands n, 1, k and q represented a multiband profile associated with $S$. cerevisiae. Similarly, as happened with yeast species $H$. guilliermondii (Table 1), Pichia kudriavzevii (band a) and S. cerevisiae (k and 1) were present from samples 3 to 15 in the three palm trees. Thus, in fresh sap $P$. kudriavzevii, $H$. guilliermondii, $S$. cerevisiae, $M$. guilliermondii and $C$. akabanensis were identified. Batches $(10,11,12,13$ and 14) from the palm tree I had the same yeast population as batches $(2,3,4,5,6,7,8,13$ and 14) from the palm tree II (Fig. 1), S. cerevisiae, H. guilliermondii, P. kudriavzevii, $C$. tropicalis, K. exigua, C. blattae, C. akabanensis and $M$. guilliermondii were identified. Batches 8, 9, 11 and 12 from the palm tree II, as well as batch 8 from palm tree III presented 10 yeast species (Fig. 1). 
Table 1 Identities of bands obtained of the yeast community from Taberna samples

\begin{tabular}{llll}
\hline Band $^{\mathrm{a}}$ & Closest relative & Identity $\%^{\mathrm{b}}$ & Source $^{\mathrm{c}}$ \\
\hline $\mathrm{c}$ & Kazachstania exigua & 100 & $\mathrm{HM} 106427.1$ \\
$\mathrm{~d}$ & Saccharomyces cerevisiae & 99 & $\mathrm{KM} 609510.1$ \\
$\mathrm{e}$ & Saccharomyces cerevisiae & 99 & $\mathrm{KJ} 530642.1$ \\
$\mathrm{~h}$ & Hanseniaspora guilliermondii & 86 & $\mathrm{KM} 210521.1$ \\
$\mathrm{i}$ & Meyerozyma guilliermondii & 92 & $\mathrm{KM} 609507.1$ \\
$\mathrm{j}$ & Candida akabanensis & 98 & $\mathrm{AB} 499000.1$ \\
$\mathrm{k}$ & Saccharomyces cerevisiae & 98 & $\mathrm{KM} 655850.1$ \\
$\mathrm{l}$ & Saccharomyces cerevisiae & 94 & $\mathrm{KJ} 530642.1$ \\
$\mathrm{n}$ & Saccharomyces cerevisiae & 99 & $\mathrm{KJ} 530642.1$ \\
$\mathrm{o}$ & Hanseniaspora guilliermondii & 100 & $\mathrm{KM} 210521.1$ \\
$\mathrm{p}$ & Hanseniaspora guilliermondii & 96 & $\mathrm{GQ249098.1}$ \\
$\mathrm{q}$ & Saccharomyces cerevisiae & 99 & $\mathrm{JX} 068683.1$ \\
$\mathrm{r}$ & Meyerozyma guilliermondii & 100 & $\mathrm{HM} 771258.1$ \\
$\mathrm{u}$ & Hanseniaspora guilliermondii & 99 & $\mathrm{KM} 210521.1$ \\
$\mathrm{w}$ & Hanseniaspora guilliermondii & 90 & KM210521.1 \\
$\mathrm{z}$ & Hanseniaspora guilliermondii & 94 & KM210521.1 \\
$\mathrm{bb}$ & Kazachstania exigua & 99 & FJ527857.1 \\
$\mathrm{dd}$ & Saccharomyces cerevisiae & 99 & KJ530642.1 \\
$\mathrm{nn}$ & Hanseniaspora guilliermondii & 94 & KM210521.1 \\
\hline
\end{tabular}

a-The letter correspond to the band letter in Fig. 1

$\mathrm{b}-$ Percentage of identical nucleotides in the sequence obtained from the DGGE band and the sequence of the closest relative found in the GenBank database.

$\mathrm{c}-$ Accession number of the sequence of the closest relative found by a blast search.

$\underline{\text { Table } 2 \text { Identification of clone sequences from DGGE bands of Taberna samples }}$

\begin{tabular}{|c|c|c|c|c|}
\hline Band $^{\mathrm{a}}$ & Clone $^{\mathrm{b}}$ & Closest relative & $\begin{array}{l}\text { Identity } \\
\%^{\mathrm{c}}\end{array}$ & Source $^{\mathrm{d}}$ \\
\hline $\mathrm{a}$ & 1 & Pichia kudriavzevii & 100 & LC015645.1 \\
\hline \multirow[t]{3}{*}{$\mathrm{b}$} & 1 & Candida akabanensis & 99 & AB499000.1 \\
\hline & 2 & Meyerozyma guilliermondii & 100 & HM771258.1 \\
\hline & 3 & Saccharomyces cerevisiae & 96 & AY526109.1 \\
\hline \multirow[t]{3}{*}{$\mathrm{f}$} & 1 & Kazachstania exigua & 100 & HM106427.1 \\
\hline & 2 & Kazachstania exigua & 99 & JQ585744.1 \\
\hline & 3 & Pichia kluyveri & 99 & KJ569591.1 \\
\hline $\mathrm{g}$ & 1 & Candida tropicalis & 95 & EF644469.1 \\
\hline \multirow[t]{2}{*}{$\mathrm{t}$} & 1 & Kazachstania exigua & 90 & JQ585744.1 \\
\hline & 2 & Candida tropicalis & 90 & KM013373.1 \\
\hline $\mathrm{v}$ & 1 & Meyerozyma guilliermondii & 99 & KF241563.1 \\
\hline \multirow[t]{5}{*}{$\mathrm{x}$} & 1 & Candida akabanensis & 93 & AB499000.1 \\
\hline & 2 & Candida akabanensis & 90 & AB499000.1 \\
\hline & 3 & Candida akabanensis & 92 & AB772160.1 \\
\hline & 4 & Hanseniaspora guilliermondii & 100 & KM210521.1 \\
\hline & 5 & Candida blattae & 99 & DQ655694.1 \\
\hline \multirow[t]{4}{*}{ aа } & 1 & Trichosporon moniliiforme & 99 & KF826528.1 \\
\hline & 2 & Meyerozyma guilliermondii & 99 & KM609507.1 \\
\hline & 3 & Hanseniaspora guilliermondii & 99 & KM210521.1 \\
\hline & 4 & Hanseniaspora guilliermondii & 99 & KM210521.1 \\
\hline \multirow[t]{2}{*}{$\mathrm{cc}$} & 1 & Saccharomyces cerevisiae & 100 & HG425339.1 \\
\hline & 2 & Hanseniaspora guilliermondii & 100 & KM210521.1 \\
\hline \multirow[t]{5}{*}{ oo } & 1 & Hanseniaspora guilliermondii & 97 & KM210521.1 \\
\hline & 2 & Candida blattae & 98 & DQ655694.1 \\
\hline & 3 & Candida blattae & 99 & DQ655694.1 \\
\hline & 4 & Candida blattae & 98 & DQ655694.1 \\
\hline & 5 & Candida intermedia & 90 & KJ794663.1 \\
\hline
\end{tabular}

a-The letter corresponds to the band letter in Fig. 1.

b-The number corresponds to the number of clones obtained with an insert of $350 \mathrm{bp}$ from each band.

c-Percentage of identical nucleotides in the sequence obtained from the clones and the sequence of the closest relative found in the GenBank database

$\mathrm{d}-$ Accession number of the sequence of the closest relative found by a blast search.

\section{Principal component analysis (PCA)}

Principal component analysis was performed using the presence-absence of the yeast species identified in each batch of Taberna production. Principal components 1 and 2 together explained $57.15 \%$ of the yeast species variation that occurred between batches and palm trees (Fig. 3). Pichia kudriavzevii, $H$. guilliermondii and $S$. cerevisiae were the dominant species. The first batch (PIB1, PIIB1, PIIIB1 and FS) from each palm tree was correlated with C. akabanensis, and batches P1B9, P1B7, P1B8, PIIB14, PIIB10, PIIB13 and cluster b (Fig. 3) were correlated with P. kluyveri. Batches from the palm tree II (PIIB3, PIIB4, PIIB5, PIIB6, PIIB7 and PIIB8) were strongly correlated with $C$. intermedia. The group including the samples FS, PIIIB1, PIIB1 and group comprising the batches PIB7, PIB8 and PIB9 were distinguished by the low number of species and because they were most distant from zero. As indicated by PCA, some batches from the same palm tree were grouped based on the yeast population similarity. This grouping showed more resemblance among initial, middle and final batches.

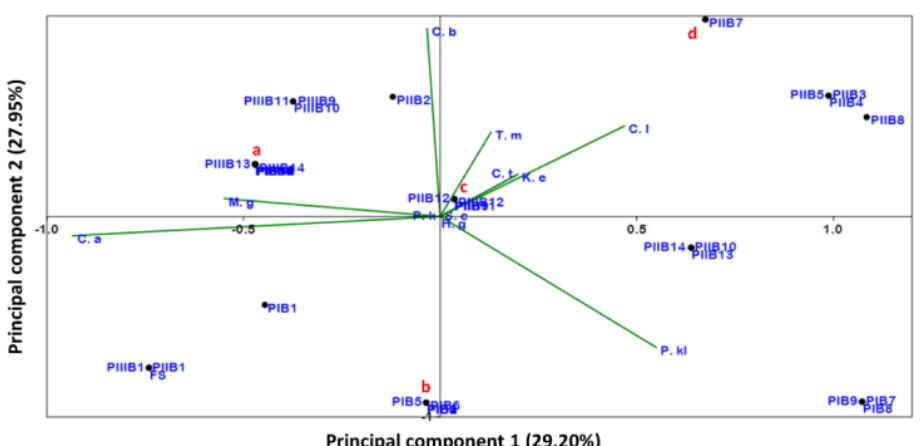

Figure 3 Principal component analysis of yeast species identified of different batches of Taberna production from three palm trees. C.b-Candida blattae, P. kl-Pichia kluyveri, S. c-Saccharomyces cerevisiae, H. g-Hanseniaspora guilliermondii, M. g-Meyerozyma guilliermondii, C. $\mathrm{t}-$ Candida tropicalis, C. aCandida akabanensis, C. i-Candida intermedia, P. k- Pichia kudriavzevii, T. mTrichosporon moniliiforme, K. e-Kazachstania exigua. Group a-(PIB10, PIB11, PIB12, PIB13, PIB14, PIIIB2, PIIIB3, PIIIB4, PIIIB5, PIIIB6, PIIIB7, PIIIB8, PIIIB13, PIIIB14), group b-(PIB2, PIB3, PIB4, PIB5, PIB6), group c-(PIIB9, PIIB11, PIIB12, PIIIB12), group d-(PIIB6, PIIB7)

\section{Frequency percentage analysis}

The frequency of positive samples of different species identified in batches from each palm tree is shown in Table 3. Saccharomyces cerevisiae, $H$. guilliermondii and $P$. kudriavzevii were common and abundant yeast species present in all batches of palm trees. In addition, in batches of palm tree I, $C$. tropicalis and $K$. exigua were detected with $93.33 \%$ frequency, followed by C. akabanensis $(80 \%)$ and $M$. guilliermondii $(66.67 \%)$. Other yeast species identified were $P$. kluyveri $(53.33 \%)$ and $C$. blattae (33.33\%). Furthermore, in batches of palm tree II, $C$. tropicalis, C. blattae and $K$. exigua were detected with a frequency of $86.67 \%$, followed by M. guilliermondii $(80 \%)$. Others species were also detected (Table 3 ). In batches of palm tree III, in addition to the three yeast species mentioned above, $M$. guilliermondii and C. akabanensis were detected with a frequency of $100 \%$, followed by C. tropicalis, C. blattae y K. exigua (Table 3). Candida intermedia was detected only in one batch of palm tree II, and T. moniliiforme was found in batches of palm trees II and III. Yeast species with a low percentage of frequency $(<35 \%)$ could be considered as sporadic strains in the process of Taberna production. 
Table 3 Number of positive samples and frequency of yeasts species present in Taberna samples from three palm trees

\begin{tabular}{|c|c|c|c|c|c|c|}
\hline \multirow[t]{2}{*}{ Species } & \multicolumn{2}{|c|}{ Palm tree I } & \multicolumn{2}{|c|}{ Palm tree II } & \multicolumn{2}{|c|}{ Palm tree III } \\
\hline & $\begin{array}{l}\text { Positive } \\
\text { samples }\end{array}$ & $\begin{array}{l}\text { Frequency } \\
(\%)^{\mathrm{a}}\end{array}$ & $\begin{array}{l}\text { Positive } \\
\text { samples }\end{array}$ & $\begin{array}{l}\text { Frequency } \\
(\%)^{\mathrm{a}}\end{array}$ & $\begin{array}{l}\text { Positive } \\
\text { samples }\end{array}$ & $\begin{array}{l}\text { Frequency } \\
(\%)^{\mathrm{a}}\end{array}$ \\
\hline S. cerevisiae & 15 & 100 & 15 & 100 & 15 & 100 \\
\hline H. guilliermondii & 15 & 100 & 15 & 100 & 15 & 100 \\
\hline M. guilliermondii & 10 & 66.67 & 12 & 80 & 15 & 100 \\
\hline C. akabanensis & 12 & 80 & 9 & 60 & 15 & 100 \\
\hline C. tropicalis & 14 & 93.33 & 13 & 86.67 & 13 & 86.67 \\
\hline C. blattae & 5 & 33.33 & 13 & 86.67 & 13 & 86.67 \\
\hline C. intermedia & $\mathrm{Nd}$ & - & 7 & 46.67 & nd & - \\
\hline P. kudriavzevii & 15 & 100 & 15 & 100 & 15 & 100 \\
\hline P. kluyveri & 8 & 53.33 & 7 & 46.67 & 3 & 20 \\
\hline K. exigua & 14 & 93.33 & 13 & 86.67 & 13 & 86.67 \\
\hline T. moniliiforme & $\mathrm{Nd}$ & - & 6 & 40 & 3 & 20 \\
\hline
\end{tabular}

\section{DISCUSSION}

The PCR-DGGE analysis of yeast population in Taberna samples permitted the identification of 11 species named $S$. cerevisiae, $C$. tropicalis, $C$. intermedia, $C$. akabanensis, $C$. blattae, $K$. exigua, $P$. kluyveri, $P$. kudriavzevii, $H$. guilliermondii, $M$. guilliermondii and $T$. moniliiforme. Three yeast species $(C$. blattae, $C$. akabanensis and T. moniliiforme) were additionally identified to the species recently reported through culture-dependent techniques (Santiago-Urbina et al. 2015). The distribution of these eleven yeast species among the batches of each palm tree, was similar but not identical, i.e. one or three yeast species were different in each batch. However, in some of these, the yeast population was identical. On the other hand, when the yeast population of each batch was compared among palm trees, a difference of one to four species was found, but in some cases, the population was identical. The growth and distribution of yeast species in Taberna fermentation is a process that depends on the types of vectors as inoculum source, and the environmental conditions. Both factors were detected at the site of the Taberna collection: environmental temperature around $38{ }^{\circ} \mathrm{C}$, and different insects, such as flies, ants, wasps, bees, dragonflies, mosquitoes, beetles and other species. Nguyen et al. (2007) suggest that Drosophila and smal beetles are the first to inoculate fresh substrates. Furthermore, the material employed in scraping the canoe and in sap collection may be contributing to the dispersion of the yeasts between palm trees. Moreover, yeast can be distributed through the air, which acts as a support medium or carrier until the microorganisms fall into the substrate (Garijo et al., 2008). Thus, the low diversity of species in the fresh sap can be attributed to limited environmental exposure, considering that this sample was collected immediately after the cavity in the stem (canoe) was created. Saccharomyces cerevisiae, P. kudriavzevii, and $H$. guilliermondii were the yeast species which predominated in all batches from the three palm trees, which was indicated by their frequency (Table 3). On the other hand, other yeast species appeared with less frequency among the samples. These results show that the sap fermentation is performed by a heterogeneous inoculum, which could be explained by different factors. First, during the collection and scraping process of the canoe, the microbiota adhered to the walls of the canoe is disrupted. Thus, the microbiota in the next batch could be different than that of the predecessor. Second, the microorganisms present in the sap and their growth can be related to their tolerance of the conditions of the sap in the canoe such as acidity, $\mathrm{pH}$, ethanol content and oxygen availability (Stringini et al., 2009; Santiago-Urbina et $\boldsymbol{a l}$., 2015), as well as the nutrient availability.

Seven genera (Saccharomyces, Hanseniaspora, Candida, Meyerozima, Kazachstania, Pichia and Trichosporon) were detected through of different batches sampled. These numbers of genera were higher than those detected in palm wine of Ghana (Candida, Pichia, Saccharomyces and Zygosaccharomyces) (Stringini et al., 2009) and lower than these (Saccharomyces, Arthroascus, Issatchenkia, Candida, Trichosporon, Hanseniaspora, Kodamaea, Schizosaccharomyces, Trigonopsis y Galactomyces) reported in Bandji (palm wine from Burkina Faso) (Ouoba et al., 2012). The results showed that number of species was similar to these reported in other palm wine produced in different countries. Although several genera are reported in palm wine, only one or three of these are predominant. In the palm wine of Ghana and Burkina Faso, $S$ cerevisiae is the predominant yeast (Stringini et al., 2009; Ouoba et al., 2012), and it is considered responsible for alcoholic fermentation (Amoa-Awua et al., 2007; Stringini et al., 2009; Ouoba et al., 2012). In Taberna the presence of non-Saccharomyces yeast species could contribute to the particular organoleptic characteristics. For example, in wine production, $H$. guilliermondii has been reported to produce higher alcohol, esters, fatty acids, and heavy sulphur compounds (Moreira et al., 2008, 2011). The environmental temperature in the place where the samples were collected was around 30 to $38^{\circ} \mathrm{C}$. Thus, Pichia kudriavzevii and C. tropicalis, two yeast species reported as producers of ethanol at high temperature (Jamai et al., 2001; Yuangsaard et al., 2013) could be contributing to ethanol production in Taberna.

In general, PCR-DGGE analysis allowed a fast detection of the yeast species involved in the Taberna fermentation. However, the technique was not free of drawbacks; a multiple banding patterns were formed for a single species and comigration of band was found. Saccharomyces cerevisiae and H. guilliermondi yielded greater number of bands (11 and 9 bands, respectively) through DGGE. Similar results have been reported by Arana-Sánchez et al. (2015), who found 7 bands associated with Hanseniaspora sp., and Papalexandratou and De Vuyst (2011) reported that the DGGE pattern of $S$. cerevisiae was composed of three bands. Multiple bands derived from a single sequence can be related with the GC-clamp primers, which undergo truncations, deletions, substitutions and insertions during PCR (Rettedal et al., 2010). Forty-base-GC-clamp primers containing multiple guanosines could form temporary quartets and four-stranded tetraplexes, leading truncations in subsequent cycles of PCR and premature elongation termination of PCR (Keniry, 2001; Rettedal et al., 2010), resulting products with different $\% \mathrm{GC}$ and therefore $T_{m}$ (Rettedal et al., 2010). Several drawbacks have been reported in some studies (Nikolausz et al., 2005; Satokari et al., 2001; Hong et al., 2007; Thompson et al., 2002; Neilson et al., 2013)

The findings suggested that PCR-DGGE is a good technique for the study of community structure, and it provides more precise information when coupled with cloning and sequencing of DGGE bands, allowing detection of multiband profile and comigration of bands. These techniques revealed the predominance of H. guiliiermondii, S. cerevisiae and P. kudriavzevii, followed by C. tropicalis and $K$. exigua in different batches of Taberna.

\section{CONCLUSION}

The present study provided new information about the yeast population associated with the Taberna fermentations, and defined the predominant yeas species determined by PCR-DGGE. This technique proved to be useful for study the structure of the yeast population. Candida blattae, C. akabanensis and T. moniliiforme were identified in the Taberna fermentation for the first time. These findings complement the information currently available on the microbiology of Taberna. The detection of predominant yeast species in all batches will be useful for the development of a yeasts starter culture to obtain a homogeneous final product.

Acknowledgments: The authors thank Serrano-Macias for providing the Taberna samples, and Alberto Sosa-Romo for providing languages help. The work was funded partially by a grant from Consejo Nacional de Ciencia y Tecnología (CONACYT) to J.A. Santiago-Urbina.

\section{REFERENCES}

Alcántara-Hernández, R. J., Rodríguez-Álvarez, J. A., Valenzuela-Encinas, F. A., Gutiérrez-Miceli, F. A., Castañón-González, H., Marsch, R., Ayora-Talavera, T., \& Dendooven, L. (2010). The bacterial community in "taberna" a traditiona beverage of Southern Mexico. Letters in Applied Microbiology, 51(5), 558-563. http://dx.doi.org/10.1111/j.1472-765x.2010.02934.x

Altschul, S. F., Madden, T. L., Shaffer, A. A., Zhang, J., Zhang, Z., Miller, W., \& Lipman, D. J. (1997). Gapped Blast and PSI-BLAST: a new generation of protein database search programs. Nucleic Acids Research, 25(17), 3389 3402. http://dx.doi.org/10.1093/nar/25.17.3389

Amoa-Awua, W. K., Sampson, E., \& Tano-Debrah, K. (2007). Growth of yeasts, lactic and acetic acid bacteria in palm wine during tapping and fermentation from felled oil palm (Elaeis guineensis) in Ghana. Journal of Applied Microbiology, 102(2), 599-606. http://dx.doi.org/10.1111/j.1365-2672.2006.03074.x 
Ampe, F., Ben Omar, N., Moizan, C., Wacher, C., \& Guyot, P. J. (1999). Polyphasic study of the spatial distribution of microorganisms in Mexican pozol, a fermented maize dough, demonstrates the need for cultivation-independent methods to investigate traditional fermentations. Applied and Environmental Microbiology, 65, 5464-5473.

Balick, M. J. (1990). Production of coyol wine from Acrocomia mexicana (Arecaceae) in Honduras. Economic Botany, 44(1), 84-93. http://dx.doi.org/10.1007/bf02861070

Arana-Sánchez, A., Segura-García, L. E., Kirchmayr, M., Orozco-Ávila, I., Lugo-Cervantes, E., \& Gschaedler-Mathis, A. (2015). Identification of predominant yeast associated with artisan Mexican cocoa fermentations using culture-dependent and culture-independent approaches. World Journal of $\begin{array}{llll}\text { Microbiology and } & \text { Biotechnology, } & 31(2), & 359-369\end{array}$ http://dx.doi.org/10.1007/s11274-014-1788-8

Byun, S. O., Fang, Q., Zhou, H., \& Hickford, J. G. H. (2009). An effective method for silver-staining DNA in large numbers of polyacrylamide gels Analytical Biochemistry, $\quad 385(1), \quad 174-175$ http://dx.doi.org/10.1016/j.ab.2008.10.024

Cocolin, L., Bisson, L. F., \& Mills, D. A. (2000). Direct profiling of the yeasts dynamics in wine fermentations. Fems Microbiology Letters, 189(1), 81-87. http://dx.doi.org/10.1111/j.1574-6968.2000.tb09210.x

Fortin, N., Beaumier, D., Lee, K., \& Greer, C. W. (2004). Soil washing improves the recovery of total community DNA from polluted and high organic conten sediments. Journal of Microbiological Methods, 56(2), 181-191. http://dx.doi.org/10.1016/j.mimet.2003.10.006

Garijo, P., Santamaria, P., López, R., Sanz, S., Olarte, C., \& Gutiérrez, A. R. (2008). The occurrence of fungi, yeasts and bacteria in the air of a Spanish winery during vintage. International Journal of Food Microbiology, 125(2), 141 145. http://dx.doi.org/10.1016/j.ijfoodmicro.2008.03.014

Hong, H., Pruden, A., \& Reardon, K. F. (2007). Comparison of CE-SSCP and DGGE for monitoring a complex microbial community remediating mine drainage. Journal of Microbiological Methods, 69(1), 52-64 http://dx.doi.org/10.1016/j.mimet.2006.11.016

Jamai, L., Sendide, K., Ettayebi, K., Errachidi, F., Hamdouni-Alami, O. TahriJouti, M. A., McDermott, T., \& Ettayebi, M. (2001). Physiological difference during ethanol fermentation between calcium alginate-immobilized Candida tropicalis and Saccharomyces cerevisiae. FEMS Microbiology Letters, 204(2), 375-379. http://dx.doi.org/10.1111/j.1574-6968.2001.tb10913.x

Keniry, M. A. (2001) Quadruplex structure in nucleic acids. Biopolymers, 56(3), 123-146. http://dx.doi.org/10.1002/1097-0282(2000/2001)56:3<123::aidbip10010>3.0.co;2-3

Moreira, N., Pina, C., Mendes, F., Couto, J. A., Hogg, T., \& Vasconcelos, I (2011). Volatile compounds contribution of Hanseniaspora guilliermondii and Hanseniaspora uvarum during red wine vinifications. Food Control, 22(5), 662667. http://dx.doi.org/10.1016/j.foodcont.2010.07.025

Moreira, N., Mendes, F., Guedes de Pinho, P., Hogg, T., \& Vasconcelos, I. (2008). Heavy sulphur compounds, higher alcohols and esters production profile of Hanseniaspora uvarum and Hanseniaspora guilliermondii grown as pure and mixed cultures in grape must. International Journal of Food Microbiology, 124(3), 231-238. http://dx.doi.org/10.1016/j.ijfoodmicro.2008.03.025

Neilson, J.W., Jordan, F.L., \& Maier, M.R. (2013). Analysis of artifacts suggests DGGE should not be used for quantitative diversity analysis. Journal of $\begin{array}{lll}\text { Microbiological } & \text { Methods, } & \text { 92(3), }\end{array}$ http://dx.doi.org/10.1016/j.mimet.2012.12.021

Nguyen, N. H., Suh, S-O., \& Blackwell, M. (2007). Five novel Candida species in insect-associated yeast clades isolated from Neuroptera and others insects. Mycologia, 99(6), 842-858. http://dx.doi.org/10.3852/mycologia.99.6.842

Nikolausz, M., Sipos, R., Révész, S., Székely, A., \& Márialigeti, K. (2005) Observation of bias associated with re-amplification of DNA isolated from denaturing gradient gels. FEMS Microbiology Letters, 244(2), 385-390. http://dx.doi.org/10.1016/j.femsle.2005.02.013

Osimani, A., Garofalo, C., Aquilanti, L., Milanović, V., \& Clementi, F. (2015). Unpasteurized comercial boza as a source of microbial diversity. International $\begin{array}{llll}\text { Journal of } \text { Food } & \text { Microbiology, } & 194, & \end{array}$ http://dx.doi.org/10.1016/j.ijfoodmicro.2014.11.011

Ouoba, L., Kando, C., Parkouda, C., Sawadogo-Lingani, H., Diawara, B., \& Sutherland, J. P. (2012). The microbiology of Bandji, palm wine of Borassus akeassii from Burkina Faso: identification and genotypic diversity of yeasts, lactic acid and acetic acid bacteria. Journal of Applied Microbiology, 113(6), 1428-1441. http://dx.doi.org/10.1111/jam.12014

Papalexandratou, Z., \& De Vuyst, L. (2011). Assessment of the species composition of cocoa bean fermentations in different cocoa-producing regions using denaturing gradient gel electrophoresis. Fems Yeast Research, 11(7), 564574. http://dx.doi.org/10.1111/j.1567-1364.2011.00747.x

Puerari, C., Magalhães-Guedes, K. T., \& Schwan, R. F. (2015). Physicochemical and microbiological characterization of chicha, a rice-based fermented beverage produced by Umutina Brazilian Amerindians. Food Microbiology, 46, 210 217. http://dx.doi.org/10.1016/j.fm.2014.08.009

Rettedal, E. A., Clay, S., \& Brözel, V. (2010). GC-clamp primer batches yield $16 \mathrm{~S}$ rRNA gene amplicon pools with variable GC clamps, affecting denaturing gradient gel electrophoresis. Fems Microbiology Letters, 312(1), 55-62. http://dx.doi.org/10.1111/j.1574-6968.2010.02097.x

Santiago-Urbina, J. A., Verdugo-Valdez, A. G., \& Ruíz-Terán, F. (2013). Physicochemical and microbiological changes during tapping of palm sap to produce an alcoholic beverage called "Taberna", which is produced in the south east of Mexico. Food Control, 33(1), 58-62. http://dx.doi.org/10.1016/j.foodcont.2013.02.010

Santiago-Urbina, J. A., Arias-García, J. A., \& Ruiz-Terán, F. (2015). Yeast species associated with spontaneous fermentation of taberna, a traditional palm wine from the southeast of Mexico. Annals of Microbiology, 65(1), 287-296 http://dx.doi.org/10.1007/s13213-014-0861-8

Satokari, R.M., Vaughan, E.E., Akkermans, A. D. L., Saarela, M., \& De Vos W. M. (2001). Bifidobacterial diversity in human feces detected by genus-specific PCR and denaturing gradient gel electrophoresis. Applied and Environmental Microbiology, 67(2), 504-513. http://dx.doi.org/10.1128/aem.67.2.504-513.2001

Solieri, L., Landi, S., De Vero, L., \& Giudici, P. (2006). Molecular assessment of indigenous yeast population from traditional balsamic vinegar. Journal of Applied Microbiology. 101(1), 63-71. http://dx.doi.org/10.1111/j.13652672.2006.02906.x

Stringini, M., Comitini, F., Taccari, M., \& Ciani, M. (2009). Yeast diversity during tapping and fermentation of palm wine from Cameroon. Food Microbiology, 26(4), 415-420. http://dx.doi.org/10.1016/j.fm.2009.02.006

Thompson, J. R., Marcelino, L. A., \& Polz, M. F. (2002). Heteroduplexes in mixed-template amplifications: formation, consequence and elimination by 'reconditioning PCR'. Nucleic Acids Research, 30(9), 2083-2088. http://dx.doi.org/10.1093/nar/30.9.2083

Valera, M. J., Torija, M. J., Mas, A., \& Mateo, E. (2015). Acetic acid bacteria from biofilm of strawberry vinegar visualized by microscopy and detected by complementing culture-dependent and culture-independent techniques. Food Microbiology, 46, 452-462. http://dx.doi.org/10.1016/j.fm.2014.09.006

Yuangsaard, N., Yongmanitchai, W., Yamada, M., \& Limtong, S. (2013) Selection and characterization of a newly isolated thermotolerant Pichia kudriavzevii strain for ethanol production at high temperature from cassava starch hydrolysate. Antonie Van Leeuwenhoek, 103(3), 577-588. http://dx.doi.org/10.1007/s10482-012-9842-8 